\title{
Canadian Citizens' Helping Intentions toward Syrian Refugees
}

\author{
Mahnoor Khan ${ }^{1}$ and Leah K. Hamilton²
}

${ }^{1}$ Werklund School of Education, University of Calgary, Calgary Alberta

${ }^{2}$ Bisset School of Business, Mount Royal University, Calgary Alberta

Corresponding author: mahnoor.t.khan@gmail.com

\section{ABSTRACT}

Since 2011, over 5 million refugees have fled civil war in Syria (UNHCR, 2018). Canada has responded to the Syrian refugee crisis by resettling over 50,000 Syrian refugees and encouraging its citizens to support the integration process. Previous research has shown that when in-group members take the perspective of an out-group it leads to increased helping intentions toward that out-group (Mashuri, Hasanah, Rahmawati, 2013). To replicate and extend these findings in a Canadian context, the current study sought to answer the question: How does national identity impact the relationship between perspective taking and helping intentions toward Syrian refugees? The results indicated that when undergraduate participants engaged in perspective taking, it led to increased financial helping intentions toward Syrian refugees, and this relationship was mediated by empathy. It was also found that individuals with a greater ethnic national identity had lower levels of political and financial helping intentions toward Syrian refugees.

\section{Introduction}

Civil war in Syria has made conditions unlivable. Since the conflict, over 150,000 have been killed, over 5 million have fled the country as refugees, and 6.6 million are displaced within the country (The Syrian Refugee Observatory for Human Rights, 2014; UNHCR, 2018). War crimes and crimes against humanity are rampant within Syria, while civilians are deliberately starved and untreated for illnesses due to denial of food and medical supplies (Amnesty International, 2016). The United Nations Refugee Agency (2016) reports that several countries have been enforcing more stringent border control to manage the number of refugees arriving. These countries include Iraq, Jordan, Lebanon, Israel, and Turkey. With the Syrian refugee crisis being one of the largest humanitarian crises of our time, it demands the support of the international community to work together and provide refuge to the millions of refugees directly affected by this crisis (UNHCR, 2016).

The 1951 Convention relating to the Status of Refugees and its 1967 protocol has made it compulsory that the legal rights of refugees be protected by signatory states (UNHCR, 2011). Canada, being one of the signatories of this con- 
vention, has gained an international reputation of welcoming and assisting refugees. Canada admitted 46,700 Syrian refugees in 2016, marking a new record since 1978, when the immigration act came into place (Puzic, 2017). The Government of Canada (2017) recognizes the increased barriers that Syrian refugees face when resettling in Canada (e.g., relatively lower English language proficiency compared to other newcomer groups), and encourages Canadian citizens to provide supportive social networks, volunteer their time, and donate in order to help the integration process of Syrian refugees. Support from individuals, communities, and service provider organizations can help refugees gain information and cultural knowledge, find employment and housing, receive social and emotional support, and learn the official languages of Canada (Government of Canada, 2017). Since the Canadian Government continues to encourage its citizens to support Syrian refugees, it is important to consider what makes Canadian citizens more or less likely to help Syrian refugees. The current study sought to answer the question: How does national identity impact the relationship between perspective taking and out-group helping intentions of Canadian undergraduate students toward Syrian refugees?

\section{Ethnic National Identity vs. Civic National Identity}

National identity is the feeling and awareness of being part of a nation, giving an individual a sense of belonging and an understanding of his or her position relative to others (Keane, 1994). The ways in which individuals construct their national identity impact the attitudes they develop toward immigrants (Esses, Hamilton \& Guacher, 2017). Smith (1991) divided the concept of national identity into two types: civic national identity and ethnic national identity. A civic national identity is defined as an inclusive identity which does not have strong ethnic attachments, and bases group membership on residency (Hansen \& Helsi, 2009). This kind of national identity is accepting of other ethnic groups living within the state, and therefore can include immigrants in the national definition of the in-group
(Esses et. al., 2017; Hansen \& Hesli, 2009). Ethnic national identity constructs in-group membership based on common ancestry and heritage, thereby excluding certain individuals such as immigrants in the definition of a national while stressing the need for nationals to be dominant in society (Meeus, Duriez, Vanbeselaere, \& Boen, 2010; Esses et al. 2018). Individuals with an ethnic national identity believe that national identity comes from being born in a particular country, living in that country for most of one's life and adopting the dominant religion of that country (Jones, 1997). In a Canadian context, possessing an ethnic national identity may include believing that to be a true Canadian, one must be born in Canada, live in Canada for most of one's life, speak French and/or English, and adhere to Christianity, which is Canada's dominant religion.

A study conducted by Hjerm (1998) found that ethnic national identity and national pride were associated with an increased risk of xenophobia, whereas having a civic national identity was linked to decreased risk of xenophobic attitudes. Furthermore, Pehrson, Vignoles \& Brown (2009) found that national identity predicts prejudice most strongly in countries where people generally believe that speaking the national language of a country is more important than citizenship in judging who should be considered a national of that country (Pehrson et. al., 2009). Pehrson and colleagues (2009) indicate that the relationship between national identity and prejudice is largely dependent on the context in which the identity is formed. This finding provides insight into how individual national identity is affected by societal factors (Pehrson et. al., 2009). Given that individual national identity impacts attitudes, xenophobia, and hostility towards immigrants, it is important to understand how national identity can also impact helping intentions that citizens have toward refugees which will be examined in the current study. This is particularly important in the context of the current study because refugees are a vulnerable immigrant group and are often most in need of assistance from citizens (Government of Canada, 2017). 


\section{Perspective Taking}

Batson et al. (2002) describe empathy as an emotional response encompassing feelings such as compassion and sympathy, which are focused on the welfare of the individual for whom empathy is being evoked. There are two kinds of empathy, state empathy and trait empathy. Trait empathy is the characteristic an individual has which allows them to experience the emotions of others across various circumstances and points in time (Westman, Shadach \& Keinan, 2012). State empathy, on the other hand, is an individual's ability to experience empathy in a particular circumstance/ situation at a specific point in time. Research has found that when state empathy is induced within an individual in regards to stigmatized groups, it improves individual attitudes toward the group (Batson, Chang, Orr, \& Rowland, 2002). State empathy is activated by perspective taking, which involves imagining another individual's feelings and thoughts (Batson et al., 2002; Mashuri et al., 2013). Perspective taking and the resulting display of state empathy lead to improved feelings, attitudes, and helping intentions toward the group member for whom state empathy is being induced, and for that out-group as a whole (Batson et al. 2002; Bilewicz, 2009; Lotz-Schmitt, Siem \& Sturmer, 2017; Mashuri et al., 2013; Mashuri, Zaduqisti \& Supriyono, 2012). Therefore, state empathy plays a mediating role in the relationship between perspective taking and out-group helping intentions (Mashuri et al., 2012). That is, state empathy is the mechanism by which perspective taking leads to increased out-group helping intentions.

The relationship between perspective taking and helping intentions has been studied robustly in the literature. According to the empathy-attitude model proposed by Batson et al. (1997), taking the perspective of an individual who is part of a stigmatized group leads to more state empathy. This increased state empathy thereby leads to positive attitudes toward the stigmatized group to which this individual belongs. In a study conducted by
Batson et al. (2002), the authors found that individuals who take the perspective of a heroin addict have higher levels of self-reported empathy, more favorable attitudes, and an increased willingness to help drug addicts by supporting the allocation of funds toward a program for people addicted to hard drugs.

Mashuri et al. (2013) conducted a study examining the relationship between perspective taking and outgroup helping intentions. The out-group consisted of citizens from Vietnam who had experienced a natural disaster, while the participants (i.e. the in-group) consisted of university students living in Indonesia. The researchers found that participants who engage in perspective taking toward Vietnamese citizens had higher levels of empathy, leading to increased financial and political helping intentions toward them.

Researchers have found that the relationship between perspective taking and out-group helping intentions is mediated and moderated by many factors including sociability, intercultural similarity and benevolence of the individual for whom perspective taking is elicited (Lotz-Schmitt et al., 2017). Thus far, the relationship between national identity and out-group helping intentions has not been examined in the literature. Therefore, in addition to examining the relationship between perspective taking and outgroup helping intentions, this study investigates the potential moderating effect of national identity on the relationship between perspective taking and out-group helping intentions.

\section{Helping Intentions}

Helping involves assisting another individual or group of people by offering resources, time, and services. Volunteering is a common form of helping where an individual dedicates their time and skills but does not get paid for their work. Given the encouragement that the Government of Canada has placed on citizens to help refugees and newcomers integrate into Canadian society, many organizations in Canada match immigrants to volunteers who provide support (Behnia, 2012). The work of vol- 
unteers in newcomer integration is so impactful that refugees and immigrants who have volunteers aiding them have more positive outcomes. These include finding employment faster, having more friends, being hopeful about the future, having better language acquisition skills, and needing less government financial assistance (Citizenship and Immigration Canada, 2004; Employment and Immigration Canada, 1986; Lanphier, 1993).

Behnia (2012) examined the experiences of volunteers by interviewing Canadian and foreign-born volunteers who work with newcomers. The author found that many volunteers expressed that they themselves are immigrants who faced challenges when adjusting to Canadian society (Behnia, 2012). Canadian-born volunteers expressed sentiments of having witnessed some of the challenges that immigrants face, which encouraged them to volunteer (Behnia, 2012). These findings are indicative that imagining the experiences of newcomers and having been in the position of a newcomer at a point in one's life, encourages individuals to volunteer and help newcomers. Therefore, studying perspective taking and its relation to helping intentions in an experimental setting is important in aiding settlement agencies in their efforts to recruit and train volunteers. Furthermore, research shows that Canadian-born volunteers were motivated to volunteer with newcomers because it made them more aware of their Canadian identity, especially because some of the volunteers were concerned that mistreatment toward newcomers gives Canada and Canadians a negative reputation (Behnia, 2012). Hence, studying the impact that national identity has on helping intentions, as well as its potential moderating effect on perspective taking and helping intentions, can provide more insight into the internal factors behind citizens' helping intentions.

\section{The Current Study}

Although the literature highlights the relationship between perspective taking and out-group helping intentions, currently there have been no studies looking at this relationship in a Canadian context toward Syrian refugees. Furthermore, the relationship between national identity and outgroup helping intentions has not been studied previously in the literature. The current study examines how national identity influences the relationship between perspective taking of Canadian undergraduate students and out-group helping intentions toward Syrian refugees. This study will add to our understanding of the factors which affect how likely Canadians are to extend help to Syrian refugees or any other newcomer group arriving in Canada.

\section{Research Question and Hypothesis}

The primary research question is: How does national identity impact the relationship between perspective taking and out-group helping intentions toward Syrian refugees? Hypothesis 1 states that there will be a main effect of perspective taking on helping intentions such that compared to their counterparts in the control condition, participants in the perspective-taking condition will demonstrate more helping intentions toward Syrian refugees. It is also hypothesized that there will be a main effect of national identity on helping intentions, such that ethnic national identity is associated with lower levels of helping intentions toward Syrian refugees (Hypothesis 2). Moreover, empathy will act as a mediator between perspective taking and helping intentions (Hypothesis 3). Lastly, there will be an interaction between perspective taking and national identity. Specifically among individuals with low ethnic national identity, there will be a simple main effect of perspective taking. That is, participants with low ethnic national identity in the perspective taking condition and the control condition will both have fairly high levels of helping intentions compared to those with a high ethnic national identity. In contrast, among individuals with a high ethnic national identity, there will be no simple main effect of perspective taking. That is, participants in the perspective taking condition and the control condition will both have fairly low 
levels of helping intentions compared to those with high ethnic national identity (Hypothesis 4).

\section{Methods}

\section{Participants}

After receiving approval from the University of Calgary's Research Ethics Board (REB17-1523), a total of 172 participants were recruited for this study through the University of Calgary's Psychology Department's Research Participation System. The initial dataset included 172 participants. Fifty-two participants were not included in the final analyses for several reasons, including not being a Canadian citizen $(N=4)$, failing to write a narrative in the perspective-taking condition $(N=3)$, failing the manipulation check $(N=6)$, and completing the study in a very short $(N=19)$ or very long $(N=17)$ amount of time. There were no multivariate outliers in the data. The final analysis included a sample of 120 participants who were randomly assigned to one of two conditions: control $(N=57)$ and perspective taking $(N=63)$. The sample consisted of $15.80 \%$ men and $83.30 \%$ women. Participants ranged from 17-30 years old $(M=19.10, S D=1.75)$. The majority of participants identified as white (47.50\%), $19.20 \%$ identified as South Asian, and $8.30 \%$ as mixed ethnicity. In regard to their religious affiliation, $35.29 \%$ of participants identified with Christianity, $37.82 \%$ stated that they had no religious affiliation, and $14.29 \%$ identified with Islam.

\section{Materials and Procedures}

Participants were directed to an external link to the study survey on Qualtrics. Participants filled out a consent form and were then provided with a short article with statistics and information regarding the current Syrian refugee crisis, including the outcomes of the war and Canada's response to the crisis. The article ended with an actual account of a Syrian refugee who has resettled into Canada. The information from this article was adapted from the UNHCR (2017), Government of Canada (2017) and Watt (2016).

Perspective Taking. All participants were provided with the article mentioned above. However, half of them were randomly assigned to the perspectivetaking condition and were provided with the following instructions prior to reading the article: "While you are reading the article try to imagine how Syrian refugees who are new to Calgary feel about what has happened and how it has affected their lives. Try not to concern yourself with attending to all the information presented. Just concentrate on trying to imagine how they would feel." After reading the article, participants in the perspective-taking condition were asked to write a short narrative about a typical day in the life of the individual mentioned in the article. Those randomly assigned to the control condition were given the following instructions prior to reading the article: "While you are reading the vignette try to be as objective as possible about what has happened to Syrian refugees who are new to Calgary and how it has affected their lives. To remain objective, do not let yourself get caught up imagining what they have gone through and how they feel as a result. Just try to remain objective and detached." This was adapted from Batson, Early \& Salvarani (1997). Those in the control condition were not told to write any sort of narrative after reading the article. Questions assessing the credibility, knowledge, comprehension, and effectiveness of the manipulation were then provided. These measures were adapted from Batson, et al., (2002), Galinsky \& Moskowitz (2000) and Mashuri et al., (2013).

Empathy. Participants completed Batson's (1997) 6-item measure of state empathy. Participants were asked to what extent they experienced emotions such as sympathy and warmth.Responses were made on a 7-point Likert scale ranging from 1(not at all) to 7 (extremely).

Helping Intentions. Participants responded to questions assessing political and financial helping inten- 
tions toward Syrian refugees in Calgary. For political helping, participants indicated how likely they would be to engage in a number of activities to aid Syrian refugees who have come to Calgary. Examples of this item ranged from "Do nothing" to "Help organize a public forum or demonstration to push for greater government help." In regard to financial helping intentions, participants were asked how likely they would be to donate in various ways to help Syrian refugees who have come to Calgary. Responses to this item ranged from "Give nothing" to "Send regular donations to Syrian refugees or sponsor a Syrian refugee." The measure of out-group helping intentions was adapted from Levine \& Thompson (2004). Respones were made on a 7-point Likert scale ranging from 1 (extremely unlikely) to 7 (extremely likely).

Ethnic National Identity. Participants' levels of ethnic national identity were assessed by asking participants to indicate to what extent they believe a number of statments were important to being truly Canadian. Examples of the measure used include "To have been born in Canada" and "To have Canadian citizenship." Responses were made on each item on a 7-point Likert scale ranging from 1 (not at all important) to 7 (extremely important). This measure was adapted from Ceobanu and Escandell (2008).

Manipulation Checks. Participants completed a number of manipulation checks to ensure the participants read the condition-specific instructions provided before the article, and to ensure that participants read the article itself. These checks were adapted from Mashuri et al. (2013). For instance, participants were asked to indicate the extent to which they agreed with the statements: "The vignette that I read spoke about the Syrian refugee crisis, and about some antiSyrian refugee sentiment which has occurred in Calgary" (1= strongly disagree to $7=$ strongly agree) and "To what extent did you concentrate on being objective towards the feelings of Syrian refugees while reading the vignette?" (1= completely unobjective to $7=$ completely objective).
The survey concluded with a questionnaire assessing demographic characteristics. After the participants completed the demographic questionnaire, they were presented with a debriefing form.

\section{Results}

Preliminary Analyses

A number of manipulation checks were conducted to ensure that participants in the control condition remained objective when reading the article, and that those in the perspective-taking condition engaged in perspective taking when reading the article. An independent samples t-test indicated that participants in the control condition were more likely to indicate that they remained objective when reading the article on Syrian refugees $(M=5.91, S D$ = 1.09), compared to those in the perspective-taking condition $(M=5.06, S D=1.66), t(107.89)=3.34, p=$ 001. Furthermore, those in the perspective-taking condition were more likely to indicate that they tried to imagine how Syrian refugees would feel while reading the article $(M=6.11, S D=1.09)$ compared to those in the control condition $(M=3.80$, $S D=1.98), t(85.34)^{1}=-7.84, p>.001$. Therefore, the perspective-taking manipulation was effective. Table 1 shows the intercorrelations among the variables. The strength of these correlations was interpreted as follows (Evans, 1996): .00-.19 very weak, .20-.39 weak, .40-.59 moderate, .60-.79 strong, .80-1.0 very strong. State empathy was moderately correlated with financial and political helping intentions, such that higher levels of state empathy were associated with greater financial and political helping intentions. Financial helping intentions were strongly correlated with political helping intentions. Ethnic national identity was weakly correlated with political helping intentions, such that higher levels of ethnic national identity were associated with lower political helping intentions. Perspective taking was moderately correlated with empathy and very weakly correlated with financial helping intentions. Gender had no significant effect on any of the dependent 
variables and therefore it was not included as a covariate. Independent samples t-tests were conducted to analyze the between-subjects' effects of the perspective-taking condition on empathy, political helping intentions and financial helping intentions.

Empathy. There was a significant main effect of perspective taking on empathy, such that those in the perspective-taking condition indicated having more state empathy $(M=5.43$, $S D=1.17)$ than those in the control condition $(M=4.28, S D=1.43), t(118)=-4.84, p<.001$.

Financial Helping Intentions. There was a significant main effect of the perspective-taking condition on financial helping intentions. Those in the perspective-taking condition indicated greater willingness to extend financial help to Syrian refugees ( $M$ $=5.21, \mathrm{SD}=0.85)$ than those in the control condition $(M=4.28, S D=1.43), t(100.63)^{1}=-2.00, p=.045$.

Political Helping Intentions. There was no significant main effect of perspective-taking condition on political helping intentions. Those in the perspective-taking condition were no more likely to offer political helping to Syrian refugees $(M=4.38, S D=1.23)$ than those in the control condition $(M=4.03, S D=1.35), p=.14$.

Table 1

Intercorrelations Between Independent Variables and Dependent Variables

\begin{tabular}{|c|c|c|c|c|c|}
\hline & Mean (SD) & State Empathy & Financial Help & Political Help & $\begin{array}{l}\text { Ethnic National } \\
\text { Identity }\end{array}$ \\
\hline State Empathy & $4.88(1.42)$ & .94 & - & - & - \\
\hline Financial Help & $5.03(1.03)$ & $.54 \star \star$ & .75 & - & - \\
\hline Political Help & $4.21(1.29)$ & $.53^{\star \star}$ & $.73 * \star$ & .83 & - \\
\hline $\begin{array}{l}\text { Ethnic National } \\
\text { Identity }\end{array}$ & 3.99 (1.25) & -.16 & -.17 & $-.25^{\star \star}$ & .78 \\
\hline PT Condition & - & $.41 * \star$ & $.18^{*}$ & .13 & -.09 \\
\hline
\end{tabular}

$\star=p<.05,{ }^{* *}=p<.001$

Perspective taking (PT) Condition was coded as follows: Control = 0, Perspective Taking = 1 State Empathy, Financial Help, Political Help, and Ethnic National Identity were measured on 7-point Likert scales.

Cronbach's Alphas appear along the diagonal.

\section{Main Analyses}

A multiple regression analysis was conducted to analyze the main and interactive effects of ethnic national identity and perspective taking on political and financial helping intentions. Ethnic national identity was mean centered in this analysis.

Financial Helping Intentions. The overall model was marginally significant, $F(3,116)=2.51, p=.06$. Condition and ethnic national identity accounted for $6.10 \%$ of the variance in financial helping intentions. A main effect of condition was found on financial helping intention such that condition accounted for a marginally significant amount of variance in financial helping intentions, $t(116)=1.88, p=$ .06. This means that participants in the perspective-taking condition tended to report greater intentions to help Syrian refugees financially. Ethnic national identity also accounted for a marginally significant amount of variance in financial helping intentions, $t(116)=-1.76, p=.08$. Participants who had a stronger ethnic national identity tended to report lower intentions to provide financial help to Syrian refugees. There was no significant interaction between ethnic national identity and condition on financial helping intentions, $t(116)=.55, p=.58$. 
Political Helping Intentions. The overall model was significant, $F=3.28, p=.02$. Condition and ethnic national identity accounted for $7.80 \%$ of the variance in political helping intentions. Condition did not account for a significant amount of variance in political helping intentions, $t(116)=1.26, p>.05$. A main effect of ethnic national identity on political helping intentions was found, such that ethnic national identity accounted for a significant amount of variance in political helping intentions, $t(116)=-2.73, p=.007$. This means that participants who had a stronger ethnic national identity tended to report lower intentions to provide political help to Syrian refugees. There was no interaction between ethnic national identity and condition on political helping intentions $t(116)=.40, p=.69$

\section{Mediation Analyses}

A regression analysis was conducted to examine the hypothesis that empathy mediates the relationship between perspective taking and financial helping intentions. It was found that perspective taking significantly predicts financial helping intentions $\beta=0.18, S E=.18, p<.05$ and that empathy is a significant predictor of financial helping intentions, $\beta=0.54, S E=.05, p<.001$. These results support the mediational hypothesis. Said differently, these results indicate that perspective taking impacts financial helping intentions because it leads participants to feel more empathy. Perspective taking no longer significantly predicted financial helping intentions after controlling for the mediator, empathy, $\beta=-.04, S E=.18, p>.05$ (see Figure 1). The indirect effect was tested using the bootstrap estimate approach (PROCESS macro, Model 4) with sample 5000. These results indicated the indirect coefficient was significant, $b=0.30, S E=077,95 \% C l=0.16$, 0.46. Perspective taking was associated with approximately .30 points higher financial helping scores as mediated by empathy. That is, participants in the perspective-taking condition (compared to the control condition) had higher levels of empathy, leading to higher financial helping scores. Therefore, empathy is the path through which perspective taking leads to financial helping intentions.

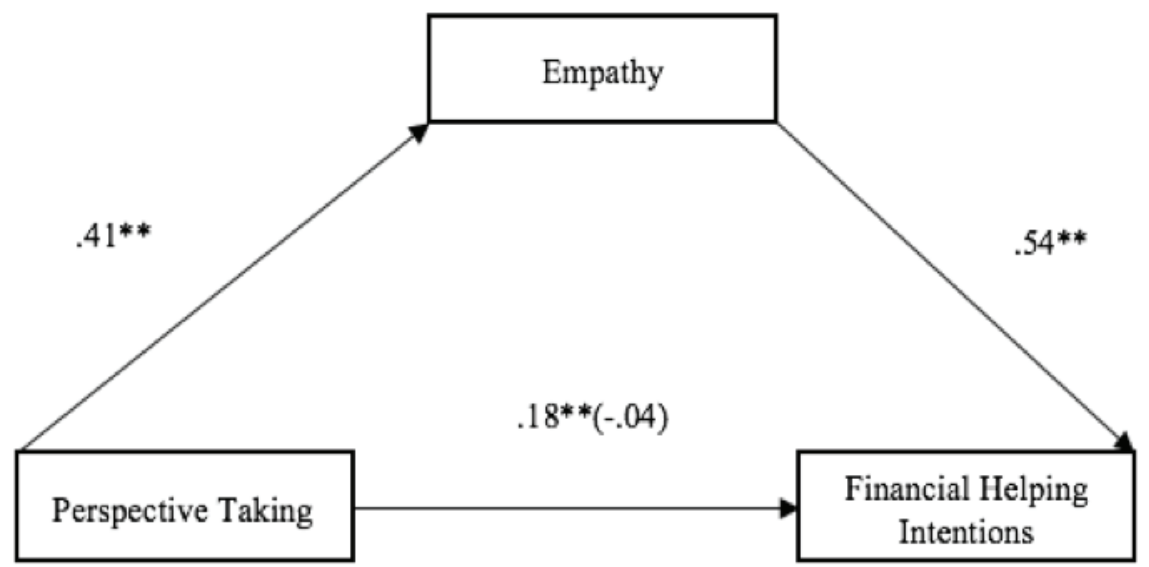

Figure 1. Standardized regression coefficients for the relationship between perspective taking and financial helping intentions as mediated by empathy. The standardized coefficient between perspective taking and helping intentions controlling for empathy is in parenthesis.

$\star * p<.01 ; * p<.05$ 


\section{Discussion}

Consistent with previous research, the current study found that taking the perspective of a Syrian refugee leads to increased financial helping intentions toward Syrian refugees and that this relationship is mediated by empathy. This study therefore replicated the findings of Mashuri et al. (2013), who found that when participants living in Indonesia took the perspective of Vietnamese individuals who had experienced a natural disaster, they had greater helping intentions toward them. The findings of the current study also support research conducted by Batson et al. (2002), who found that when individuals took the perspective of a stigmatized out-group member, they had increased helping behaviours toward the out-group.

Both Mashuri et al. (2013) and Batson et al. (2002) found that empathy was the mechanism through which perspective taking led to increased outgroup helping intentions. The current study further confirmed that the relationship between perspective taking and financial helping intentions was mediated by empathy. Previous research has found that individual factors, such as political orientation and in-group warmth impression of the individual engaging in perspective taking, can influence whether perspective taking affects one's helping intentions toward an out-group, (LotzSchmitt et al. 2017; Mashuri et al. 2012). However, the impact of national identity on the relationship between perspective taking and helping intentions has not been studied thus far. In the current study, Canadian undergraduate students with an ethnic national identity had lower levels of political and financial helping intentions toward Syrian refugees. The current findings showcase that ethnic national identity is not only associated with hostility and xenophobic attitudes toward immigrants and newcomers, but negatively impacts helping intentions as well (Carter \& Perez, 2016; Hjerm, 1998.)

Since national identity is influenced by the context in which it is constructed, it is important that governmental institutions promote an inclusive national identity so that more citizens aid in the resettlement of refugees. Furthermore, contextual factors such as the political climate, public attitudes, and media messages need to support newcomer integration by portraying newcomers as being nationals of the country. This can be accomplished by highlighting newcomers' contributions to Canadian society.

Contrary to the hypothesis, ethnic national identity did not interact with perspective taking to influence political and financial helping intentions toward Syrian refugees. Importantly, this finding illustrates that perspective taking can influence the financial helping intentions of individuals, even if they possess an ethnic national identity. Therefore, perspective taking may be utilized to garner increased support toward newcomers and refugees, which may override the negative influence that ethnic national identity has on political and financial helping intentions.

The current findings have practical implications for settlement agencies, non-profit organizations, and governmental institutions seeking support from citizens to help aid refugee integration into Canadian society. These institutions are encouraged to gain support from Canadian citizens by encouraging them to take the perspective of a refugee and consider the many challenges that refugees face prior to and during their resettlement in Canada. These institutions can do this by providing real life accounts of refugees who have immigrated to Canada, and they can instruct their audience to put themselves in the shoes of the refugee. Behnia (2012) comments that some Canadian-born volunteers who work with immigrants do so because they have witnessed some of the challenges that immigrants face. This finding is relevant to the current study, suggesting that when citizens witness or are provided knowledge about the challenges faced by refugees and take the perspective of a refugee, they are more likely to engage in various forms of helping intentions and actions toward them. 
Although the implications of this study are important, there are several limitations in this study which must be considered. First, participants completed this study on their own time in an unsupervised setting. Due to this, some individuals had to be excluded because they took an extremely short or long amount of time to complete the study. Second, this study examined political and financial helping intentions of individuals, however it did not examine their actual behaviours. The conclusions of this study may not be consistent if looking at physical helping actions of individuals as opposed to their intentions. Only political and financial helping intentions were examined, although there are other ways helping could be measured which may lead to different findings. For instance, previous research has found that Canadian volunteers who work with immigrants provide emotional support, information, help newcomers find jobs, and offer friendship (Behnia, 2012). These kinds of behaviours or helping intentions were not covered in the present study. It would be difficult to generalize the findings of this study to all Canadians due to the age group of the sample, as this study represents a fairly young demographic, who may be more prone to pro-immigration policies (Esipova, Ray, Pugliese, \& Tsabutashvili, 2015). Lastly, only Syrian refugees were examined as the target newcomer group and these results may not be generalizable to other newcomers who have arrived in Canada.

There are a number of next steps which can be taken to address the limitations mentioned above. For instance, future research can replicate the current study in order to assess helping intentions toward other newcomer groups which have come to Canada. This research would help to ensure the generalizability of our current findings, strengthening our recommendations for governmental organizations and resettlement agencies to utilize perspective taking when recruiting volunteers and garnering citizens' support in immigrant integration. Considering the differences amongst immigrants and refugees in their portrayal in the media and public opinions, it would be interesting for future research to investigate whether perspective taking and national identity would be as predictive of helping intentions for other immigrants or refugee groups as it was for Syrian refugees. Moreover, future research can also investigate if perspective taking and national identity influence helping actions of Canadian citizens toward refugees and immigrants, rather than just intentions. The kinds of helping actions which can be assessed may include providing helpful information, tangibly helping newcomers find a job, and helping newcomers develop their English skills. Refugees from across the world depend on countries like Canada to find hope in times of despair, security in times of fear, and stability in times of uncertainty. Canada relies on the collective efforts of its citizens to aid the resettlement of refugees. A representative of the UN Refugee Agency in Canada, Jean-Nicolas Bueze, has commended Canada on its commitment to Syrian refugee resettlement and emphasized the importance of civil society working with the government in this process. Bueze stated that, "Without this support, scores of refugees would have been left in life-threatening situations and without any hope. Canada has again shown the world that successful resettlement is possible, particularly when government and civil society work together..." (UNHCR, 2017). 


\section{Notes}

1. Levene's test for equality of variance was violated. 


\section{References}

Amnesty International (2016). Syria's refugee crisis in numbers. Retrieved from https://www.amnesty. org/en/latest/news/2016/02/syrias-refugee-crisis-in-numbers/

Batson, C. D., Chang, J., Orr, R., \& Rowland, J. (2002). Empathy, attitudes, and action: Can feeling for a member of a stigmatized group motivate one to help the group? Personality and Social Psychology Bulletin, 28(12), 1656-1666. https://doi.org/10.1177/014616702237647

Batson, C. D., Early, S., \& Salvarani, G. (1997). Perspective taking: Imagining how another feels versus imaging how you would feel. Personality and Social Psychology Bulletin, 23(7), 751-758. https:// doi.org/10.1177/0146167297237008

Behnia, B. (2012). Volunteering with newcomers: The perspectives of Canadian-and foreign-born volunteers. Canadian journal of nonprofit and social economy research, 3(2). https://doi.org/10.22230/cjnser.2012v3n2a116

Bilewicz, M. (2009). Perspective taking and intergroup helping intentions: The moderating role of power relations. Journal of Applied Social Psychology, 39(12), 2779-2786. https://doi.org/10.1111/ j.1559-1816.2009.00548.x

Carter, N. M., \& Pérez, E. O. (2016). Race and nation: How racial hierarchy shapes national attachments. Political Psychology, 37(4), 497-513. https://doi.org/10.1111/pops.12270

Ceobanu, A. M., \& Escandell, X. (2008). East is West? National feelings and anti-immigrant sentiment in Europe. Social Science Research, 37(4), 1147-1170. https://doi.org/10.1016/j. ssresearch.2008.01.002

Citizenship and Immigration Canada. (2004). Evaluation of host program. Ottawa, ON: Citizenship and Immigration Canada.

Employment and Immigration Canada. (1986). First report on the host program: Pilot projects in London, Winnipeg and Regina. Ottawa, ON: Employment and Immigration Canada.

Esipova, N., Ray, J., Pugliese, A., \& Tsabutashvili, D. (2015). How the world views immigration. Retrieved from International Organization for Migration website: https://publications.iom.int/system/files/ how_the_world_gallup.pdf

Esses, V. M., Hamilton, L. K., \& Gaucher, D. (2017). The global refugee crisis: Empirical evidence and policy implications for improving public attitudes and facilitating refugee resettlement. Social Issues and Policy Review, 11(1), 78-123.

Evans, J. D. (1996). Straightforward Statistics for the Behavioral Sciences. Brooks/Cole Publishing: Pacific Grove, Calif.

Galinsky, A. D., \& Moskowitz, G. B. (2000). Perspective-taking: decreasing stereotype expression, 
stereotype accessibility, and in-group favoritism. Journal of Personality and Social Psychology, 78(4), 708. http://dx.doi.org/10.1037/0022-3514.78.4.708

Government of Canada (2017). Refugees and asylum. Retrieved from https://www.canada.ca/en/ immigration-refugees-citizenship/services/refugees.html

Hansen, H. E., \& Hesli, V. L. (2009). National identity: Civic, ethnic, hybrid, and atomised individuals. Europe-Asia Studies, 61(1), 1-28. https://doi.org/10.1080/09668130802532894

Hjerm, M. (1998). National identities, national pride and xenophobia: A comparison of four Western countries. Acta Sociologica, 41(4), 335-347. https://doi.org/10.1177/000169939804100403

Jones, F. L. (1997). Ethnic diversity and national identity. The Australian and New Zealand Journal of Sociology, 33(3), 285-305. https://doi.org/10.1177\%2F144078339703300302

Keane, J. (1994). Nations, nationalism and citizens in Europe. International Social Science Journal, 46(2), 169-184.

Lanphier, C. M. (1993). Host groups: Public meets private. In The International Refugee Crisis (pp. 255272). Palgrave Macmillan, London.

Levine, M., \& Thompson, K. (2004). Identity, place, and bystander intervention: Social categories and helping after natural disasters. The Journal of Social Psychology, 144(3), 229-245. https://doi. org/10.3200/SOCP.144.3.229-245

Lotz-Schmitt, K., Siem, B., \& Stürmer, S. (2017). Empathy as a motivator of dyadic helping across group boundaries: The dis-inhibiting effect of the recipient's perceived benevolence. Group Processes \& Intergroup Relations, 20(2), 233-259. https://doi.org/10.1177/1368430215612218

Mashuri, A., Zaduqisti, E., \& Supriyono, Y. (2012). Perspective-taking and outgroup helping: The moderating role of warmth impression and outgroup status. International Journal of Research Studies in Psychology, 1(3), 7-20. https://doi.org/10.5861/ijrsp.2012.238

Mashuri, A., Hasanah, N., \& Rahmawati, I. (2013). The effect of out-group status and perspective-taking on empathy and out-group helping. International Journal of Research Studies in Psychology, 2(2), 3-14. https://doi.org/10.5861/ijrsp.2012.149

Meeus, J., Duriez, B., Vanbeselaere, N., \& Boen, F. (2010). The role of national identity representation in the relation between in group identification and out group derogation: Ethnic versus civic representation. British Journal of Social Psychology, 49(2), 305-320. https://doi. org/10.1348/014466609X451455 
Pehrson, S., Vignoles, V. L., \& Brown, R. (2009). National identification and anti-immigrant prejudice: Individual and contextual effects of national definitions. Social Psychology Quarterly, 72(1), 2438. https://doi.org/10.1177/019027250907200104

Puzic, S. (2017, April 24). Record number of refugees admitted to Canada in 2016, highest since 1980. CTV News. Retrieved from http://www.ctvnews.ca/canada/record-number-of-refugees-admittedto-canada-in-2016-highest-since-1980-1.3382444

Smith, A. D. (1991). National identity. University of Nevada Press.

The Syrian Refugee Observatory for Human Rights (2014). Retrieved from http://www.syriahr.com/ en $/ ? p=4462$

UNHCR (2017). Canada's 2016 record high level of resettlement praised by UNHCR. Retrieved from http:// www.unhcr.org/news/press/2017/4/58fe15464/canadas-2016-record-high-level-resettlementpraised-unhcr.html

UNHCR (2016). Syria conflict at 5 years: the biggest refugee and displacement crisis of our time demands a huge surge in solidarity. Retrieved from http://www.unhcr.org/news/press/2016/3/56e6e3249/ syria-conflict-5-years-biggest-refugee-displacement-crisis-time-demands.html

UNHCR (2011). The 1951 Convention Relating to the Status of Refugees and its 1967 Protocol. Retrieved from http://www.unhcr.org/4ec262df9.pdf

UNHCR (2018). Syria Emergency. Retrieved from http://www.unhcr.org/syria-emergency.html

Watt, M. (2016, March 13). Starting over: One Syrian refugee family's story, in their own words. CBC News. Retrieved from http://www.cbc.ca/news/canada/manitoba/syrian-refugee-family-ownwords -1.3475875

Westman, M., Shadach, E., \& Keinan, G. (2013). The crossover of positive and negative emotions: The role of state empathy. International Journal of Stress Management, 20(2), 116. http://dx.doi. org/10.1037/a0033205 